\title{
Cloud Scavenging Effects on Aerosol Radiative and Cloud-nucleating Properties - Final Technical Report
}

Principal Investigators:

John A. Ogren, NOAA/ESDL, Boulder, CO 80305

Patrick J. Sheridan, NOAA/ESDL, Boulder, CO 80305

Co-Investigator:

Elisabeth Andrews, University of Colorado, CIRES, Boulder CO 80305

Acknowledgments:

PNNL (loan of instrumentation - ASP infrastructure)

Date: February 26, 2009

\begin{abstract}
:
The optical properties of aerosol particles are the controlling factors in determining direct aerosol radiative forcing. These optical properties depend on the chemical composition and size distribution of the aerosol particles, which can change due to various processes during the particles' lifetime in the atmosphere. Over the course of this project we have studied how cloud processing of atmospheric aerosol changes the aerosol optical properties. A counterflow virtual impactor was used to separate cloud drops from interstitial aerosol and parallel aerosol systems were used to measure the optical properties of the interstitial and cloud-scavenged aerosol. Specifically, aerosol light scattering, back-scattering and absorption were measured and used to derive radiatively significant parameters such as aerosol single scattering albedo and backscatter fraction for cloud-scavenged and interstitial aerosol. This data allows us to demonstrate that the radiative properties of cloud-processed aerosol can be quite different than pre-cloud aerosol. These differences can be used to improve the parameterization of aerosol forcing in climate models.
\end{abstract}




\section{Cloud Scavenging Effects on Aerosol Radiative and Cloud-nucleating Properties}

Oklahoma, where the wind comes sweepin' down the plains,

Where the wavin' wheat,

Can sure smell sweet,

When the wind comes right behind the RAIN...

\section{Introduction/Background}

In addition to their detrimental effects on human health and environmental aesthetics, atmospheric particles scatter and absorb solar radiation and can thus directly affect climate. The direct radiative effect of aerosol particles (i.e., the radiative flux change per unit aerosol optical depth) is potentially equal in magnitude but opposite in sign to that of greenhouse gases (IPCC, 2001). The direct radiative forcing by aerosols is controlled both by the concentration of particles in the atmosphere and by the optical characteristics of those particles. Cloud scavenging is the major removal mechanism for anthropogenic aerosols and the scavenging efficiency depends on the size and chemical composition of the particles. Likewise, aerosol optical properties are controlled by particle size and chemical composition. The strength of direct and indirect aerosol forcing depends, in part, on the partitioning in clouds of interstitial and cloud-scavenged particles. Because of the relatively long lifetime of interstitial aerosol compared to cloud-scavenged particles, the direct forcing related to interstitial aerosol can impact a larger region. Alternatively, particles which are scavenged or nucleate to droplets impact indirect forcing through higher cloud droplet numbers, smaller cloud droplet size, and subsequent higher cloud albedo and longer cloud lifetimes.

We hypothesize that differential cloud scavenging (i.e., preferential removal of an aerosol type based on its inherent characteristics such as size or composition) causes systematic changes in aerosol optical properties. Through a series of experiments we evaluate the magnitude of those changes for different aerosol types. In on-going collaboration with other ASP investigators, the processes controlling differential cloud scavenging are being diagnosed, the results from which will be used to improve the representation of the evolution of aerosol optical properties in global chemical transport and climate models. In this report, we first summarize the general concept of aerosol processing by clouds, including the anticipated effects of cloud processing on specific aerosol optical properties. Next we describe the results from the Cumulus Humilis Aerosol Processing Study (CHAPS) campaign in Oklahoma (June 2007) in the context of other, related field campaigns. These results fall into three categories: (1) cloud processing of aerosol (the focus of our project) (2) comparisons across platforms and aerosol types (3) instrument performance.

\subsection{Cloud processing of aerosol particles}

Clouds and aerosol particles can interact in several ways, including nucleation scavenging, coagulation, diffusion and washout. Clouds can also provide the interface for heterogeneous chemical reactions resulting in mass addition to scavenged particles (e.g., Kreidenweis et al., 2003) and multi-modal size distributions (e.g., Feingold and 
Kreidenweis, 2000). The relative dominance of each of these processes depend on both the characteristics of the cloud and the aerosol; however, Noone et al. (1992b) have shown that nucleation scavenging is likely to be the primary in-cloud mechanism for particle removal and will be the main focus here. Nucleation scavenging is the process whereby an aerosol particle grows into a cloud droplet in a supersaturated environment. The ability of an aerosol particle to act as a cloud condensation nucleus (CCN) depends largely on its size and on the fraction of water-soluble material in the particle. Nucleation scavenging is most effective for large soluble particles and less effective for smaller or insoluble particles. When precipitation falls from the cloud, large soluble particles are preferentially removed from the system and the aerosol that remains when the cloud subsequently dissipates is enriched in smaller and insoluble particles. As described below, this enrichment has implications for the two optical properties controlling the radiative forcing efficiency of the aerosol, namely, the single-scattering albedo (SSA) and the backscatter fraction (BFR). SSA describes the relative contributions of scattering and absorption to light extinction, and BFR describes the amount of sunlight that is scattered back to space when the sun is directly overhead. Measurements on ambient aerosols typically yield SSA values around 0.9 , with SSA as low as 0.4 for diesel soot and as high as 1.0 for pure sulfate aerosols. At visible wavelengths, BFR decreases from 0.5 for particles much smaller than the wavelength of light to nearly zero for particles much larger than the wavelength of light; measurements on ambient aerosols typically reveal backscatter fractions in the range 0.1-0.2. Based on the size and composition dependencies of nucleation scavenging and aerosol optical properties, we test the hypothesis that nucleation scavenging systematically reduces the single-scattering albedo and increases the backscatter fraction of the unscavenged aerosol. The results of these tests are described in section 3.

A main focus of cloud/aerosol research has been on how aerosols influence cloud properties, e.g., indirect effect (e.g., Charlson et al., 1987; Rosenfeld, 2000); here we explore how clouds influence the properties of aerosol particles. How clouds process aerosols is a function not only of the characteristics of the aerosol particles, but also of the cloud properties. Three cloud parameters that are important for aerosol processing are liquid water content, cloud drop size and updraft velocity. Kasper-Giebl et al. (2000) have measured different scavenging efficiencies for sulfate and carbonaceous aerosol and noted that these scavenging efficiencies varied with cloud LWC. To the extent that coagulation and impaction processes control aerosol scavenging by cloud drops, cloud drop size is directly important for aerosol/cloud drop interactions, although Noone et al., (1992b) suggest these processes are not particularly important. Cloud drop size also plays a role in cloud lifetime (being a determining factor for when precipitation starts). Updraft velocity controls the supersaturation reached in the cloud, which in turn determines which particles are activated (i.e., scavenged by in-cloud nucleation). Feingold and Kreidenweis (2000) have shown that lower updraft velocities can result in more nucleation scavenging during aerosol cycling through clouds.

\subsection{Aerosol scattering, back-scattering and backscatter fraction}

Aerosol total scattering (i.e., the sum of forward and backward scattering) gives an indication of how much aerosol is present. Observed total scattering values range from 
less than $10 \mathrm{Mm}^{-1}$ in clean environments to a factor of 40 or more higher in polluted or dusty environments. The amount of scattering varies not only as a function of location but can also vary significantly at the same location depending on sources, transport and meteorology (e.g., Delene and Ogren, 2002). Back-scattering (light scattered in the direction of the light source) is, like total scattering, related to the amount of aerosol present; however, back-scattering is also a strong function of particle size. The ratio of total scattering to back-scattering, the 'backscatter fraction (BFR)' is thus primarily an indicator of particle size, with higher values suggesting the presence of smaller particles. BFR is one integral property of the angular distribution of light scattered by aerosols, also called the phase function, used in modeling the impact of aerosols on radiative fluxes and climate. Another common parameterization of the phase function in radiative forcing calculations is the asymmetry parameter. The BFR can be related to asymmetry parameter using the methodology of Marshall et al. (1995).

Delene and Ogren (2002) have shown that the BFR varies systematically with amount of total light scattering - it tends to be higher for clean conditions and lower for high aerosol loadings (Figure 1a). One possible explanation for this observation is that cloud processing preferentially scavenges and removes larger particles, resulting in cleaner conditions with a post-cloud aerosol size distribution shifted towards smaller particles. Conditions characterized by higher aerosol concentrations that have not undergone cloud processing retain a broader aerosol size distribution including larger particles. Noone et al. (1992c) showed that, in a polluted cloud, in-cloud scavenging preferentially removes larger particles while particles smaller than $0.3 \mu \mathrm{m}$ remain as interstitial aerosol. Hallberg et al. (1994) also noted preferential scavenging of larger particles, although they found that interpretation of their results were complicated by possible influences of aerosol composition/mixture state and entrainment of drier air into the cloud. Results like this are consistent with observations of Delene and Ogren (2002).

\subsection{Aerosol absorption and single scattering albedo}

While particles that are primarily light scattering have been studied extensively, the influence of light absorbing particles in the atmosphere is still not well understood. Elemental carbon (EC) particles, a component of soot, are the primary particulate absorbers of solar radiation in the atmosphere. EC particles are typically generated by combustion and can be natural (e.g., biomass burning) or anthropogenic (e.g., diesel soot) in origin. According to the IPCC report (2001), combustion aerosol and mineral dust are the main components contributing to the uncertainty in estimates of direct aerosol forcing. Regardless of the source of light absorbing particles in the atmosphere, a better understanding of their lifetime and processing in the atmosphere will improve our ability to model the aerosol SSA, increasing accuracy in climate forcing calculations. Haywood and Shine (1996) have shown that the sign of the radiative forcing due to aerosols depends on SSA. Here we address one aspect of the EC lifecycle in the atmosphere: cloud processing of EC-containing aerosol.

Differential cloud scavenging as a function of aerosol hygroscopicity may result in changes in the relative amount of absorption to scattering in the unscavenged aerosol (Ogren and Charlson, 1983) and may be one cause of the systematic dependence of SSA 
on loading (Figure 1b) observed by Delene and Ogren (2002). Figure 2 illustrates the two extreme conditions for EC/cloud interactions. Figure 2a shows the case where the EC (e.g., soot) is hydrophobic and unlikely to act as CCN or to coagulate with cloud drops (e.g., Noone et al., 1992a). The EC may remain after other particles are removed by nucleation scavenging, resulting in a relatively blacker interstitial and post-cloud aerosol. In Figure 2b "aged" EC can become coated with other species such as sulfates or soluble organics (through condensation and/or coagulation processes) making the composite soot particles larger and more hygroscopic and thus more likely to become incorporated into cloud or fog droplets. Conversion of soot aerosols from hydrophobic to hygroscopic particles is the rate limiting step in this mechanism (e.g., Ogren and Charlson, 1983; Cooke and Wilson, 1996). There is a competition between the conversion rate to a hygroscopic particle and onset of precipitation. If precipitation removes water-soluble substances that could coagulate with or condense upon EC before the EC has acquired a hygroscopic coating, then the conversion of EC to a hygroscopic form will take much longer.

Both experimental and modeling studies support the notion of competition between particle conversion rates and onset of precipitation. Noone et al. (1992a) noted that EC particles remained primarily in the interstitial aerosol during a fog experiment in Italy. In a mountain cloud experiment, Hallberg et al. (1994) investigated whether chemical composition, specifically EC and sulfate species, influenced the partitioning of particles between cloud drops and interstitial air. They found that sulfate-containing particles were scavenged by cloud droplets three times more efficiently than EC, although they were unable to determine whether this difference was due solely to chemical composition or to differences in the size distribution of the two aerosol species. In a different study in a more remote location, Gieray et al. (1997) found that sulfate and soot aerosol had similar scavenging fractions, although sulfate aerosol was still scavenged slightly more efficiently than soot. More recently, Laj et al. (2001) found that EC particles tended to remain as interstitial aerosol in ice clouds; and Ogren et al. (2004) showed a strong correlation between decreases in SSA and presence of cloud. Modeling work by Chung and Seinfeld (2002) is consistent with these in situ observations. They compared measurements of carbonaceous aerosol with values predicted using a global circulation model with tracer transport capabilities. The model consistently under-predicted carbonaceous aerosol concentrations. The authors suggest that one source of the underestimation could be the model parameterization of wet scavenging (i.e., the model may over-estimate the potential of clouds to scavenge EC).

The uncertainties in EC scavenging reported in the literature may be due to the fact that the characteristics of EC particles can change during their lifetime in the atmosphere. Condensation of soluble materials on the surface of EC particles and/or coagulation with soluble particles can increase the hygroscopicity of the EC-containing particles. Gieray et al. (1997) and references therein, note the increasing fraction of EC scavenged by clouds with increasing distance from the aerosol source. Alternatively, condensation of hydrophobic film forming compounds on aerosol particles may reduce the number of cloud drops activated (i.e., the number of aerosol particles scavenged by nucleation) 
(Feingold and Chuang, 2002). Optical measurements alone will not provide information about chemical characteristics of the EC, but will provide one piece of the puzzle.

\subsection{Hypotheses}

Cloud processing affects aerosol chemical and microphysical properties. The observed changes depend on the initial or pre-cloud nature of the particles (i.e., mixing state, composition, size distribution, etc.) as well as the nature of the cloud (e.g., liquid water content). It follows that aerosol optical properties will also be affected by cloud processing. Below we list several hypotheses describing the influence of clouds on aerosol optical properties:

1. BFR will increase in cloud scavenged air and interstitial aerosol.

2. SSA will decrease in cloud-scavenged air and interstitial aerosol.

3. Distinct aerosol types will interact differently with clouds, but the general trends will likely be the same. For example, SSA will decrease for all aerosol types but the decrease will be less if the absorbing aerosols have aged and are internally mixed with soluble aerosols.

4. The radiative properties of cloud-processed aerosol are quite different than precloud aerosol.

Table 1 summarizes the measurements and calculations needed to test these hypotheses. We describe the results from testing these hypotheses and document how aerosol optical properties change with cloud processing in the first part of the Results section (section 3a).

\subsection{CHAPS Campaign and Instrumentation}

A series of three field experiments (see Table 2) were performed to determine the effect of cloud/fog processing on the optical properties of several types of aerosols. The aerosol studied in these field campaigns included clean marine (Point Reyes, CA), highly absorbing, urban-influenced (near Manchester, UK) and less absorbing, urban-influenced (near Oklahoma City). The clean marine aerosol had a fairly broad size distribution so changes in particle size due to cloud processing would be easy to see. The urbaninfluenced aerosol provided a good opportunity to look at changes in SSA due to cloud processing. Below we briefly describe each of the measurement locations and then summarize the basic measurements made for each campaign.

\subsection{Measurement Location - Oklahoma City, OK}

The final field experiment we performed occurred as part of the Cumulus Humilis Aerosol Processing Study (CHAPS) campaign in Oklahoma in June 2007. The stated goal of the CHAPS campaign was to "study interactions of aerosols on clouds and of clouds on aerosols" with particular interest in how emissions from a mid-sized city affected these interactions. Thus it meshed nicely with the hypotheses we wished to explore. The major difference in this campaign compared to the two previous experiments was that in this case the platform was the ASP G-1 aircraft managed by Battelle. The aircraft platform enabled us to seek the clouds rather than waiting for the clouds to come to us. A study of cloud chord length (pers. comm., L. Berg, 2006) based on climatological measurements made at DOE's Southern Great Plains facility suggested 
that the cumulus humilis clouds would be frequent enough and sizeable enough for the proposed investigations on aerosol-cloud interaction.

The G-1 aircraft was based in Ponca City, OK. From there the plane would fly various flight patterns based on meteorology, in-flight observations and mission goals. The G-1 flew 12 missions over the course of the month. The most common flight pattern was a series of profiles (walls) upwind and downwind of Oklahoma City intended to sample clean (upwind) conditions and the urban plume (downwind). Each profile was designed to include an above- cloud, below-cloud and two in-cloud legs. The two in-cloud legs were included so that the aerosol mass spectrometer (AMS), which measured nonrefractory aerosol chemistry, could spend one leg sampling interstitial aerosol from the isokinetic (ambient) inlet and one leg sampling cloud drop residuals through the CVI inlet. During the campaign the weather tended not to cooperate with the general goals of CHAPS - June 2007 was when Texas, Oklahoma and Kansas all had devastating floods. As one scientist noted the clouds tended to be more of the 'cumulus humongous' variety than of the cumulus humilis type. Nonetheless, based on in-flight observations and some preliminary data QC, the G-1 successfully intercepted the Oklahoma City plume.

\subsection{Basic measurements}

This experiment involved a set of tandem inlets, one designed to sample ambient or interstitial aerosol (depending whether fog was present or not) and one (the CVI) designed to sample cloud drop residuals. Downstream of these inlets were some duplicate instrumentation and a switching system, which allowed non-duplicate instruments to switch between inlet systems in order sample both interstitial and cloud drop residuals when the inlets were in cloud. Table 2 lists the aerosol and ancillary instrumentation deployed during CHAPS. Figure 3 is a schematic of the instrument sampling set up at Point Reyes. It is representative of the system used for CHAPS, although the instruments and inlet switching were slightly different.

Our research focus is primarily on the aerosol optical properties (Table 2 includes some of the relevant instrumentation deployed by collaborators). The basic aerosol optical property measurements required to address our hypotheses are the partitioning of aerosol light absorption, total light scattering, and hemispheric backscattering between interstitial air and the cloud droplets. These measurements are the fundamental components needed to calculate aerosol radiative forcing. The specific aerosol optical property measurements we made during these field intensives to obtain the data for hypothesis testing are listed in Table 1. The directly measured quantities permit us to derive several key aerosol properties important in aerosol radiative forcing, including SSA and BFR. Measurements were conducted so that both the within-cloud (i.e., aerosol incorporated into clouds droplets and interstitial aerosol particles) and without-cloud aerosol were sampled. Our in-cloud experimental approach was to sample simultaneously two size fractions of particles and droplets. Nucleation-scavenged particles grow rapidly above cloud base to diameters larger than a few micrometers, while the unscavenged particles remain in the size fraction below a few micrometers. On the G-1, the isokinetic inlet was efficient for diameters less than $\sim 5 \mu \mathrm{m}$ (e.g., low turbulence inlet (Wilson and Seebaugh, 2001)), while the cut size of the airborne CVI was $\sim 11 \mu \mathrm{m}$ diameter. For both the surface and 
airborne platforms there is an unavoidable size gap between the interstitial and cloud drop samples. Ideally, without the gap, the sum of these two size fractions would represent the total aerosol in the cloud allowing for closure. These complementary samples are subsequently dried to the same relative humidity (ca. 40\%), and the optical properties of the dried particles are measured with duplicate sets of instrumentation (Figure 3). A similar system was used in the Po Valley experiment in 1989 (Heintzenberg, 1992) and more recently at Åre, Sweden in the summer of 2003 (Ogren et al., 2004).

In addition to aerosol optical properties, the total particle number, $\mathrm{N}_{\text {tot }}$, (measured using a $\mathrm{CN}$ counter) was measured downstream of both the aerosol and CVI inlets. Measurement of $\mathrm{N}_{\text {tot }}$ provides a sanity check on the measurements. Because the sum of interstitial particle number and cloud droplet number should be $\mathrm{N}_{\text {tot }}$ (in an ideal sampling system) we have a constraint to help us identify sampling problems. For example, on the airplane during in-cloud legs, drop shattering in the isokinetic inlet resulted in the interstitial particle number being significantly higher than the ambient particle concentration. Additionally, measurement of $\mathrm{N}_{\text {tot }}$ can help in determining whether the airmass is changing over the course of the cloud event (e.g., Noone et al., 1992b).

\subsection{The CVI inlet}

The counterflow virtual impactor was conceived by one the PIs (Ogren) in the early 1980s (Ogren et al., 1985). Its original application was aircraft-based sampling of Arctic clouds during the Marginal Ice Zone experiment (MIZEX-84). This airborne deployment was followed two years later by surface-based experiments which included characterization of the aerosol particles that result from evaporation of cloud droplets (Noone et al., 1988) and size dependent chemistry of cloud droplets (Ogren et al., 1989). In the last several decades, many researchers have found the CVI to be a useful technique for cloud/aerosol studies. A comprehensive list of CVI references is at http://www.esrl.noaa.gov/gmd/aero/pubs/cvi.html. Some examples include: studies of the composition of ice nuclei (e.g., Christensson et al., 2000), studies of ship (e.g., Noone et al., (2000) and aircraft exhaust (e.g., Twohy and Gandrud, 1998). Ogren et al. (2004) utilized a ground-based CVI to investigate differences in interstitial versus cloudscavenged SSA at a mountain top site in Sweden.

\subsection{Results}

\subsection{Cloud processing of aerosol}

Our hypotheses focused on characterizing the changes in aerosol optical properties associated with cloud/fog processing. Thus, our major goal was to use observational studies to determine the ranges of the cloud-induced changes to the aerosol optical properties for different types of aerosols. We present results for each of our hypotheses below. There are many other changes to the aerosol which can occur with atmospheric cloud/fog processing (e.g., chemical reactions); while the investigation of these changes was beyond the scope of our specific project, complementary measurements made by collaborators during the campaigns allow us to begin to investigate some of the 
mechanisms responsible for the observed changes. We present some of these results as well.

\subsubsection{Cloud scavenging decreases the amount of interstitial aerosol}

Clouds form on atmospheric aerosol. If light extinction is taken as a surrogate for aerosol amount then one would expect the light extinction for interstitial aerosol to be less than that for the same aerosol measured in clear sky condition. Figure 4a shows differences in aerosol light extinction for ambient and interstitial air for the five sites at which we have made these types of measurements. The figure shows the CHAPS results in addition to results from two other ASP deployments (Point Reyes and Holme Moss) and two other sites. (Mount Åreskutan was a field site in Sweden, the aerosol could be categorized as remote continental; Chebogue Point measurements were made on the southwest coast of Nova Scotia and the aerosol was primarily aged urban plume from the east coast of the US). In all cases we see that extinction decreases in the interstitial air implying the cloud is scavenging aerosol.

\subsubsection{SSA will decrease in cloud-scavenged air and interstitial aerosol}

Figure $4 \mathrm{~b}$ shows differences in SSA Again a mostly consistent picture emerges - the SSA tends to be lower in the interstitial air than it is for the cloud free air. For CHAPS there is very little difference between the median values of interstitial and clear sky aerosol - it's within the uncertainty of the scattering and absorption measurements used to calculate SSA. However, the $5^{\text {th }}$ and $25^{\text {th }}$ percentiles do suggest a lower SSA for the interstitial aerosol. Thus, as we hypothesized, the clouds appear to be less likely to incorporate absorbing aerosol than scattering aerosol resulting in darker aerosol in the interstitial air.

\subsubsection{BFR will increase in cloud scavenged air and interstitial aerosol}

Figure 4c shows differences in BFR for ambient and interstitial air for the same five sites. BFR increased for interstitial aerosol relative to that measured for cloud free aerosol. This is consistent with our hypothesis suggesting that the clouds tend to preferentially scavenge the larger aerosol, leaving smaller particles in the interstitial air. For CHAPS, again, there is very little difference between the interstitial and clear air measurements. One possible explanation for the small changes in BFR and SSA during CHAPS is that the aerosol was relatively small and well-mixed.

\subsubsection{Radiative properties of cloud-processed aerosol are different than pre-cloud aerosol}

Figure $4 \mathrm{~d}$ shows aerosol radiative forcing at the top of the atmosphere. This was calculated using the formulation of Haywood and Shine (1995) for radiative forcing efficiency and multiplying by aerosol light extinction for the five sites. For this calculation the only variables are BFR, SSA and light extinction - for aerosol comparison purposes everything else (zenith angle, surface albedo, etc) are assumed to be identical for all sites. These calculations are for low surface albedo, which exaggerates backscattering effects over absorption. Even so, the overall effect of scavenging is a reduction of the top-of-atmosphere cooling. Although the BFR and SSA values for the CHAPS campaign showed slighter variations between clear and interstitial properties than observed for some of the other campaigns there is still an obvious difference 
between the clear sky and cloud processed aerosol forcing during CHAPS because of changes in aerosol amount due to scavenging.

Based on the data from CHAPS as well as two previous ASP campaigns and two nonASP campaigns we can summarize the effects of cloud scavenging on aerosol as follows:

\section{Aerosol amount}

- Strongly decreases

Absorption vs. scattering

- Dominant absorber is insoluble, less efficiently scavenged

- Size-dependencies favor larger reduction of scattering than absorption

\section{Angular scattering}

- Size-dependence of angular scattering favors scavenging of forward-scattering particles

- Unscavenged particles more likely to scatter backwards (more energy loss to space)

\section{Radiative forcing}

- Decrease in the magnitude of cooling over dark surfaces

\subsection{Comparisons across platforms and aerosol types}

CHAPS involved multiple aircraft and several ground based platforms. Here we show comparisons of the aerosol optical property profiles measured using identical instruments on the G-1 and on DOE's In-situ Aerosol Profiles (IAP) Cessna 206. This type of comparison can provide information on whether June 2007 was a representative year as well as looking at aerosol profiles at various distances from a major source (OKC). The IAP aircraft had flown $\sim 600$ vertical profiles over the Southern Great Plains ACRF site, $100 \mathrm{~km}$ north of Oklahoma City, between March of 2000 and June 2007 when CHAPS ended. The G-1 flew 8 profiles within $50 \mathrm{~km}$ of Oklahoma City during the CHAPS campaign. Figure 5 shows that the profiles measured by the G-1 tended to have higher scattering than those measured over the ACRF site, as one would expect for air sampled closer to a major source. The Ångstrom exponent was lower (indicative of larger particles) closer to Oklahoma City. This was somewhat surprising as urban air is assumed to be dominated by small particles formed by gas phase processes such as gas-to-particle conversion and condensation, however, one might expect to sample larger particles produced by mechanical processes such as brake wear and dust generation.

For CHAPS the G-1 had the advantage of flying upwind and downwind of the Oklahoma City plume where the plume could be identified by several measurements on the aircraft including $\mathrm{CO}$ concentration and particle number concentration. Figure 5 also shows observed differences in light scattering and Ångström exponent for when the G-1 was sampling within and outside of the Oklahoma City plume. There were three flights where the plume was observed. The plume was identified using the criteria where $\mathrm{CO}>125 \mathrm{ppb}, \mathrm{CN}>2500 \mathrm{~cm}^{-3}$ and altitude $<1350 \mathrm{~m}$. The scattering was higher (more aerosol) inside the plume than outside of it. Consistent with the comparison between IAP and the G-1, the aerosol tended to be larger (lower Ångström exponent) inside the plume, possibly due to being closer to the source. Berg et al. (2009) have also shown that the 
SSA tends to be lower (darker aerosol) in the OKC plume (note: they used a slightly different criteria to identify the plume).

\subsection{Instrument performance}

Several of the platforms at CHAPS utilized identical instruments for measuring aerosol optical properties. Although the platforms made measurements in different locations and often at different times, it was assumed that during analysis data from one platform would complement that from other platforms by filling in spatial and/or temporal gaps in measurements. Thus as part of the preparation for CHAPS instrument intercomparisons on all the nephelometers (measure scattering) and PSAPs (measure absorption) were done a week prior to the start of the campaign on location in Oklahoma. These tests would also lead to better data quality by catching any last minute instrument problems prior to the start of the campaign.

A large (57 liter) stirred mixing chamber was used to mix and distribute test aerosols to the various scattering and filter-based absorption instruments involved in the CHAPS campaign. These instruments were limited to TSI Model 3563 integrating nephelometers and Particle Soot Absorption Photometers (PSAP, Radiance Research, Inc.). These instruments were from ground-based sampling systems (e.g., SGP Central Facility and Edmond Surface Site), as well as airborne systems from the G-1, Twin Otter, and IAP Cessna aircraft.

The test aerosols included soot from a small kerosene lamp, ammonium sulfate generated using an ultrasonic humidifier, and ambient aerosols when sufficient amounts of particulate material were in the air. Tests were performed with each of these systems run alongside a NOAA mobile reference system, which consisted of a TSI nephelometer and a PSAP. Tests were conducted in the Greenwood Aviation hangar in Ponca City, OK; in the Aerosol Trailer at the SGP Central Facility, and at the PNNL trailer in Edmond, OK.

The objective of these tests was to identify major instrument problems before the start of the Intensive, so that repairs or recalibrations could be performed if necessary and valid data would be obtained during the experiment. The objective was not to determine calibration or adjustment factors for the various instruments. TSI integrating nephelometers make scattering measurements with a total analytical uncertainty from all sources of around 10\%. The PSAP filter-based absorption measurement has a reported total analytical uncertainty of approximately $20 \%$.

The comparisons we performed (Figure 6) showed that the measurements from all instruments were comparable within these uncertainties, with the exception of the reference ("dry") nephelometer at the SGP Central Facility. This nephelometer measured scattering from 10-16\% lower than the NOAA Mobile Reference nephelometer. The cause for this discrepancy was determined to be photomultiplier tubes (PMTs) that were old and less sensitive than they should be. New PMTs were not available at the site at that time for replacement. This comparison result should be considered if/when fly-by comparisons of the SGP Central Facility with aircraft systems are made. Basically, the two PNNL nephelometers tested agreed pretty well with the NOAA nephelometer, and 
agreement might have been even better if more comprehensive servicing had been performed or if all nephelometers had been recalibrated in Leipzig during an intercomparison workshop in March 2007.

\subsection{Conclusions}

The ASP aims to improve predictive climate modeling through improved understanding of the aerosol radiative forcing of the climate. Here we have addressed one of the uncertainties in the distribution and fate of aerosols (i.e., cloud processing) and explored how it relates to changes in aerosol optical properties and radiative fluxes for multiple aerosol types. Based on the results from CHAPS as well two other ASP field campaigns and two additional field experiments, we have been able to assess our general hypotheses. We found that clouds tend to scavenge larger, less scattering aerosol leaving the darker, smaller aerosol in the interstitial air. In terms of intrinsic aerosol properties this means that BFR increases and SSA decreases in cloud scavenged air and interstitial aerosol. As BFR and SSA are both important factors in aerosol radiative forcing it follows and we showed here that the radiative properties of the cloud-processed aerosol are quite different than the pre-cloud aerosol. We observed cloud processing of aerosol for multiple aerosol types and while the magnitude of the changes differ as a function of aerosol type the general trends are the same.

Complementary measurements made by our collaborators, e.g., aerosol chemistry, is already allowing us to explore how particle composition influences water/aerosol interactions with implications for both direct and indirect forcing. As we collaborate with other ASP investigators using this large data set, some other ideas we hope to explore are:

1) improved parameterization of EC processing by clouds

2) better understanding of size and composition dependent aerosol processing by clouds

3) reduced uncertainty in EC cycle and lifetime in atmosphere

4) better understanding of the cloud processing mechanisms affecting aerosol properties

Incorporation of findings from these planned explorations into climate models will reduce the uncertainty in predictive modeling capabilities and improve our ability to identify the amount of aerosol radiative forcing versus other forcing factors such as greenhouse gases. 
Tables

Table 1 Optical measurements and derived aerosol optical properties

\begin{tabular}{|c|c|c|}
\hline & Measured properties & $\begin{array}{l}\text { Instrument providing } \\
\text { measurement }\end{array}$ \\
\hline$\sigma \mathrm{sp}$ & $\begin{array}{l}\text { Total aerosol light scattering at three wavelengths }(450 \text {, } \\
550,700 \mathrm{~nm}) \text { at low }(<40 \%) \text { relative humidity }\end{array}$ & Integrating nephelometer \\
\hline бap & $\begin{array}{l}\text { Aerosol light absorption at three wavelengths }(467,530 \text {, } \\
660 \mathrm{~nm}) \text { at low }(<40 \%) \text { relative humidity }\end{array}$ & $\begin{array}{l}\text { Particle soot absorption } \\
\text { photometer (PSAP) }\end{array}$ \\
\hline \multirow[t]{2}{*}{$\begin{array}{l}\text { obs } \\
\mathrm{p}\end{array}$} & $\begin{array}{l}\text { Hemispheric back-scattering at three wavelengths }(450, \\
550,700 \mathrm{~nm}) \text { at low }(<40 \%) \text { relative humidity }\end{array}$ & Integrating nephelometer \\
\hline & Derived properties & \\
\hline SSA & $\begin{array}{l}\text { The aerosol single-scattering albedo, defined as } \sigma_{\mathrm{sp}} /\left(\sigma_{\mathrm{ap}}+\right. \\
\sigma \mathrm{sp}) \text {, describes the relative contributions of scattering and } \\
\text { absorption to the total light extinction. Purely scattering } \\
\text { aerosols (e.g., sulfuric acid) have values of } 1 \text {, while very } \\
\text { strong absorbers (e.g., elemental carbon) have values } \\
\text { around } 0.3 \text {. }\end{array}$ & $\begin{array}{l}\text { Need nephelometer + PSAP } \\
\text { measurements }\end{array}$ \\
\hline$B F R$ & $\begin{array}{l}\text { Radiative transfer models commonly require one of two } \\
\text { integral properties of the angular distribution of scattered } \\
\text { light (phase function): the asymmetry factor } g \text { or the } \\
\text { hemispheric backscatter fraction BFR. The hemispheric } \\
\text { backscatter fraction BFR is defined as obsp/osp. The } \\
\text { asymmetry factor is the cosine-weighted average of the } \\
\text { phase function, ranging from a value of - } 1 \text { for entirely } \\
\text { backscattered light to }+1 \text { for entirely forward-scattered } \\
\text { light and can be estimated using BFR (Marshall et al., } \\
\text { 1995) }\end{array}$ & $\begin{array}{l}\text { Need nephelometer } \\
\text { measurements }\end{array}$ \\
\hline
\end{tabular}

Table 2 Relevant instrumentation for CHAPS

\begin{tabular}{|c|c|c|c|}
\hline type & Instrument & Measurement & Mentor \\
\hline Aerosol & $\begin{array}{l}\text { TSI Nephelometer } \\
\text { Radiance Research PSAP } \\
\text { TSI CNC }^{1,2} \\
\text { Particle absorption photo- } \\
\text { acoustic cell }^{2} \\
\text { DMT CCN }^{5} \\
\text { Aerodyne Aerosol Mass } \\
\text { Spectrometer } \\
\text { Time resolved aerosol } \\
\text { collector (TRAC) } \\
\text { Scanning mobility particle } \\
\text { sizer }\end{array}$ & $\begin{array}{l}\text { Spectral scatter, } \\
\text { backscatter } \\
\text { Spectral absorption } \\
\text { Number concentration } \\
\text { absorption } \\
\text { CCN number } \\
\text { concentration } \\
\text { Non-refractory aerosol } \\
\text { chemistry } \\
\text { Elemental aerosol } \\
\text { composition } \\
\text { Aerosol size } \\
\text { distribution }\end{array}$ & $\begin{array}{l}\text { NOAA } \\
\text { NOAA } \\
\text { NOAA } \\
\text { LANL } \\
\text { PNNL } \\
\text { PNNL/BNL } \\
\text { PNNL } \\
\text { BNL }\end{array}$ \\
\hline $\begin{array}{l}\text { Cloud } \\
\text { and met }\end{array}$ & $\begin{array}{l}\text { PMS Forward scattering } \\
\text { spectrometer probe (FSSP) }\end{array}$ & $\begin{array}{l}\text { Cloud drop number } \\
\text { and size }\end{array}$ & BNL \\
\hline
\end{tabular}




\begin{tabular}{|l|l|l|l|}
\hline $\begin{array}{l}\text { Meteorology } \\
\text { Tunable diode laser } \\
\text { hygrometer }^{1,4,6}\end{array}$ & $\begin{array}{l}\text { Temperature, RH, } \\
\text { pressure, winds } \\
\text { Cloud drop LWC, } \\
\text { water vapor mixing } \\
\text { ratio }\end{array}$ & $\begin{array}{l}\text { PNNL } \\
\text { NOAA, PNNL }\end{array}$ \\
\hline
\end{tabular}

${ }^{1}$ Mentored by NOAA as part of our research

${ }^{2}$ Duplicate instrument (i.e., one for each inlet)

${ }^{3}$ Downstream of a switch, enabling switching between CVI and AIA inlet

${ }^{4} \mathrm{CVI}$ inlet only

${ }^{5}$ AIA inlet only

${ }^{6}$ External G-1 probe

Note: As part of ASP infrastructure PNNL provided duplicate aerosol optics

(nephelometer, PSAP, CNC) systems (counting the G-1 instruments as part of ASP infrastructure) 


\section{Figures}

Figure 1 Systematic variation of (a) aerosol back-scattering fraction and (b) single scattering albedo with light scattering (after Delene and Ogren, 2002). BND = Bondville, IL; SGP =, Lamont, OK (ARM-CART site); WSA=Sable Island, Canada; NSA= Barrow, AK (ARM site).

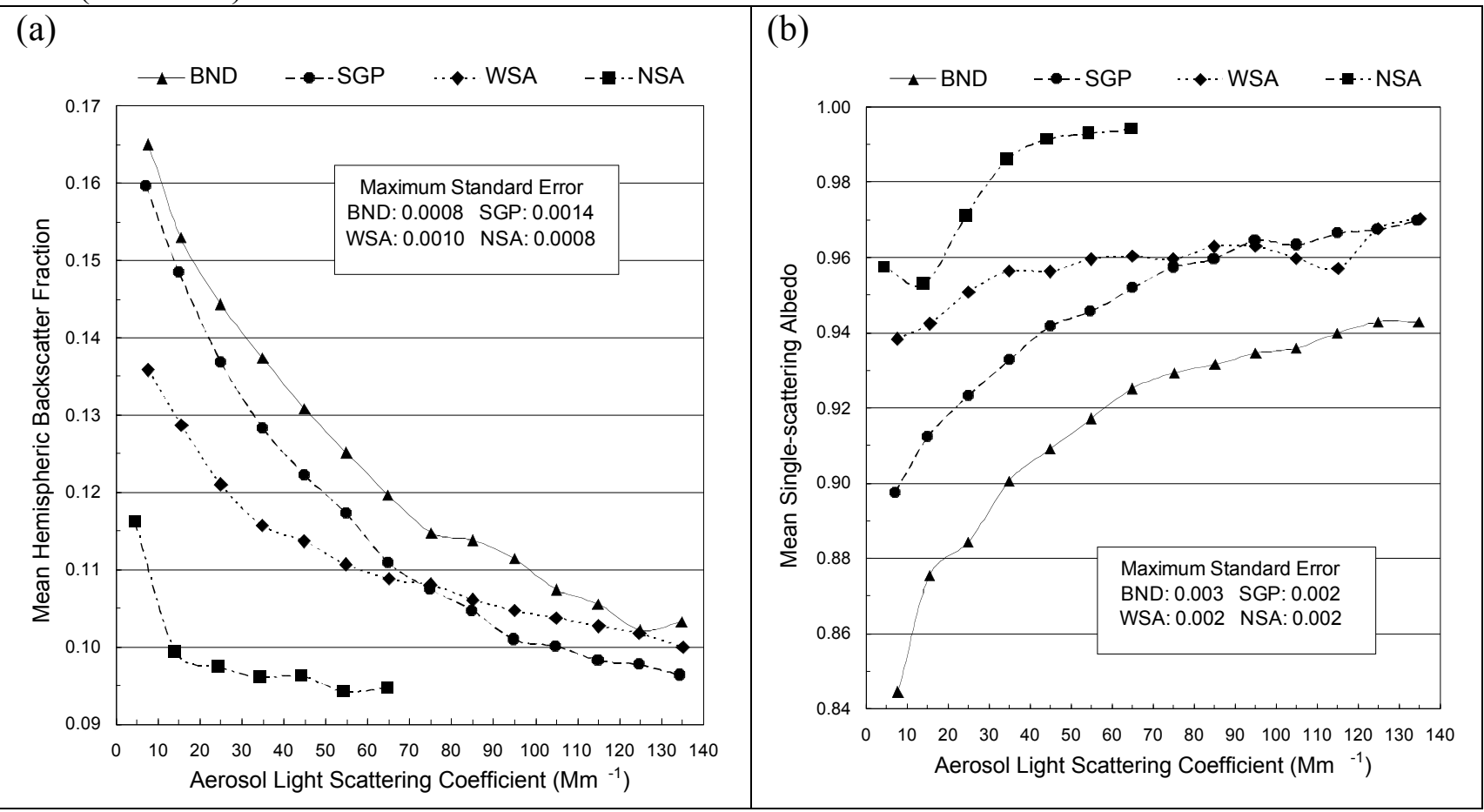


Figure 2 Exaggerated schematic of difference in processing for uncoated and coated EC particles.
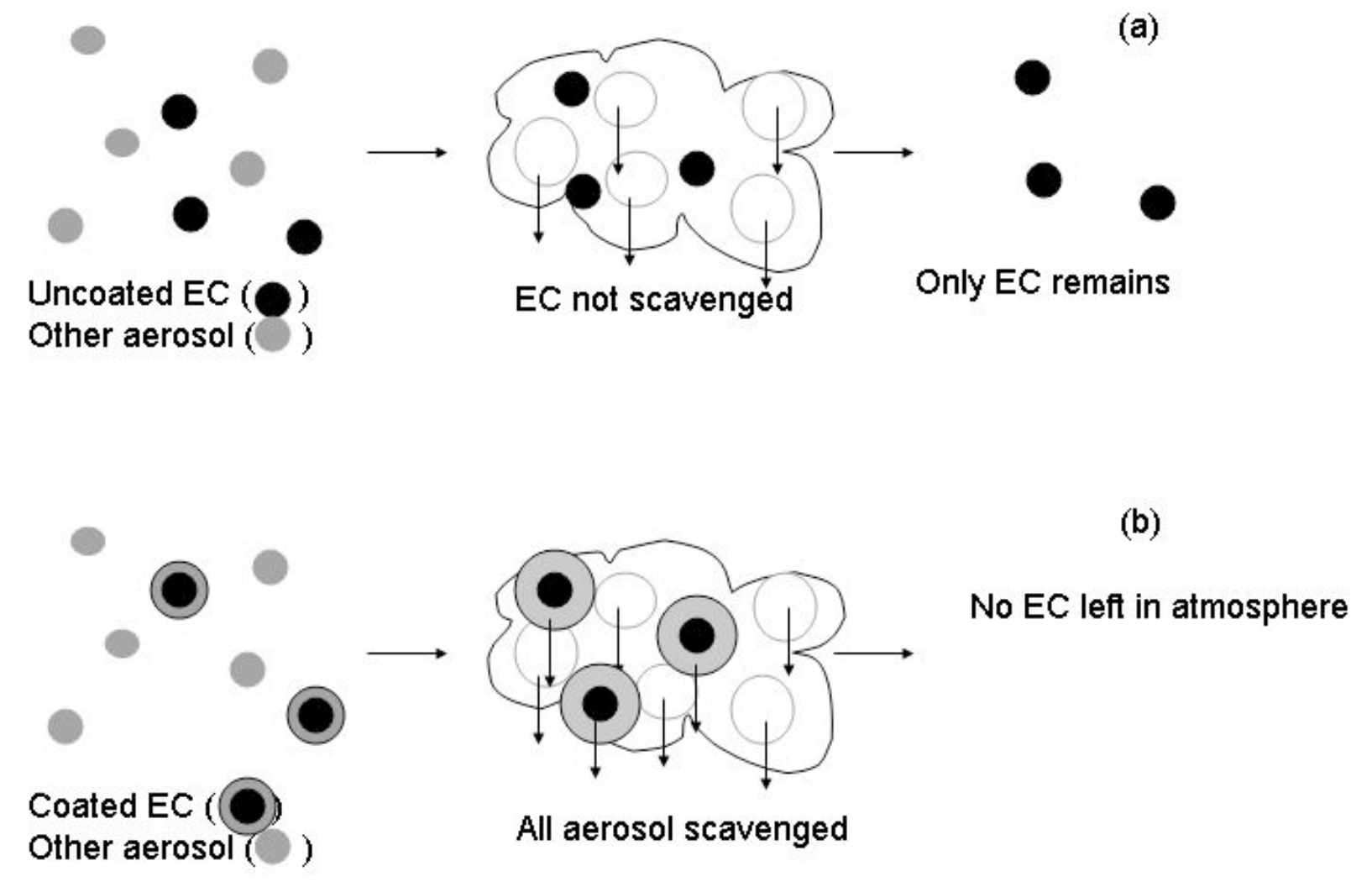
Figure 3 Schematic of CHAPS aerosol sampling system (AMS switched between CVI and Isokinetic inlet).

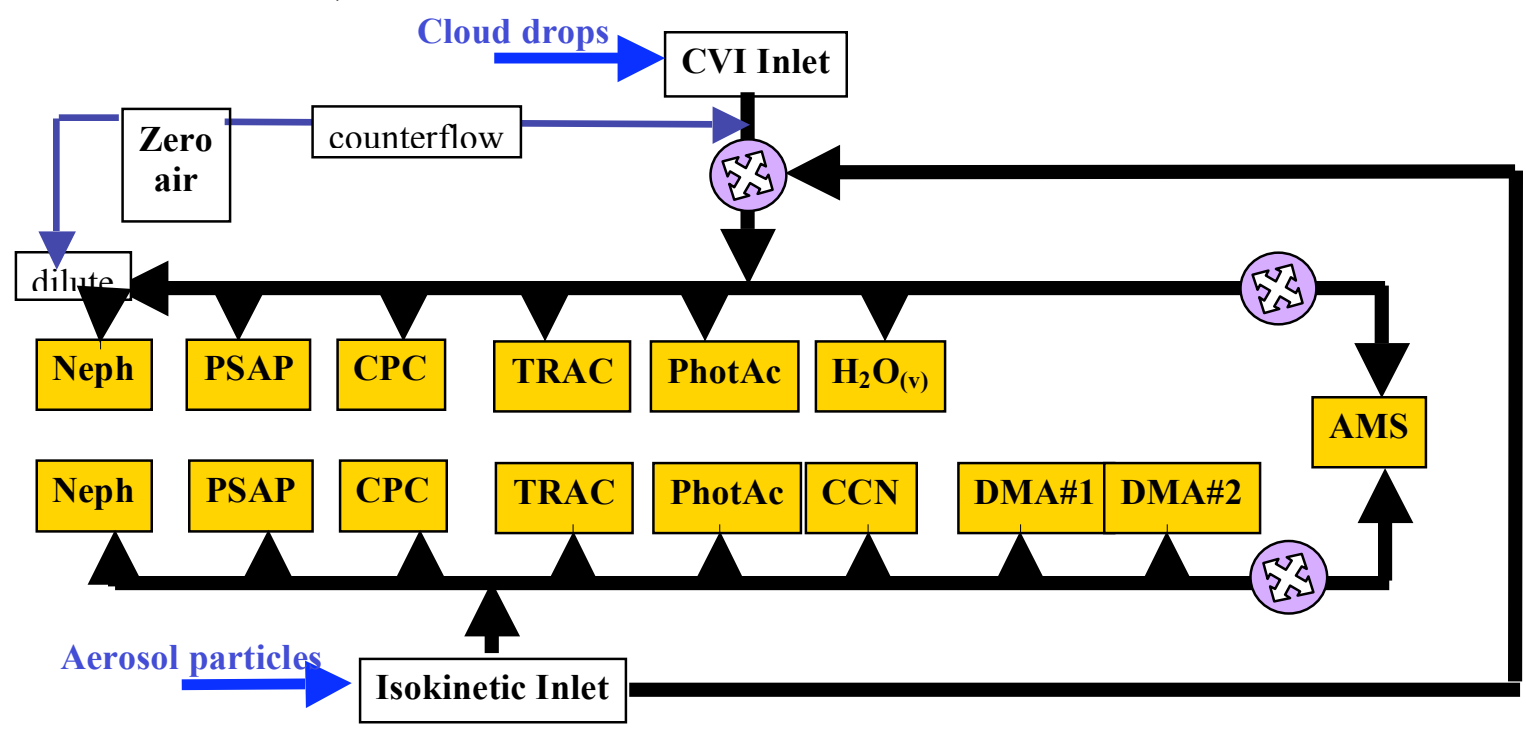

Figure 4 Comparison of clear sky (yellow) and interstitial (blue) aerosol properties (a) extinction (b) single scattering albedo (c) backscattering fraction (d) forcing. Data are from five sites: Mount Åreskutan (ARE), Chebogue Point (CBG), Pt Reyes (PYE), Holme Moss (HLM) and CHAPS (OKC). Box-whiskers represent $5^{\text {th }}, 25^{\text {th }}$, median, $75^{\text {th }}$ and $95^{\text {th }}$ percentiles.

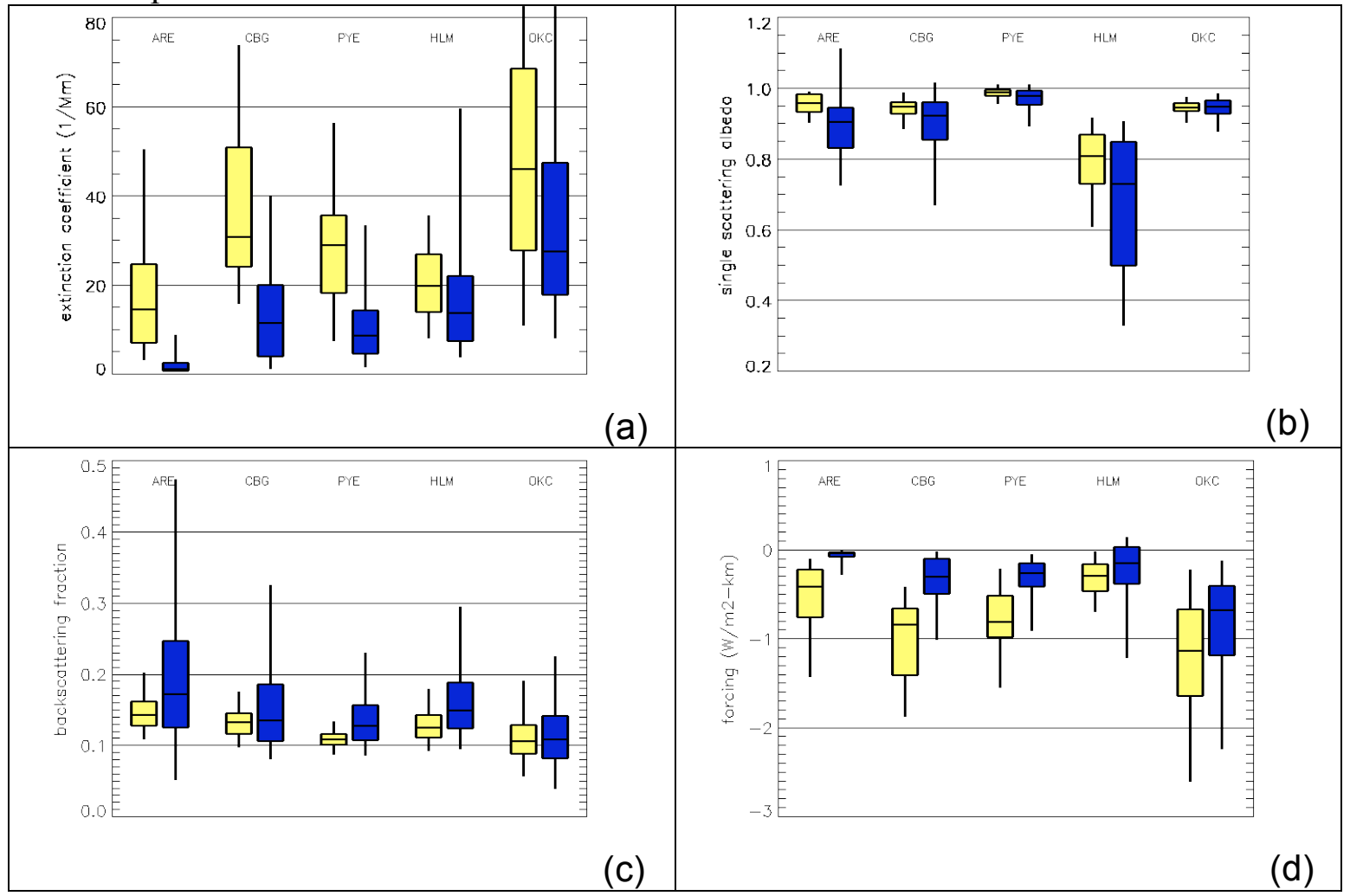


Figure 5 Comparison of G-1 clear conditions aerosol optical property profiles for June 2007 (red) with various subsets of IAP profiles (blues and greens). Dashed red lines show $25^{\text {th }}$ and $75^{\text {th }}$ percentiles of G-1 profile values. Dark blue vertical line shows median value when the G-1 was not in the Oklahoma City plume; Yellow vertical line shows median value when G-1 was sampling Oklahoma City plume. (From Andrews et al., 2007)
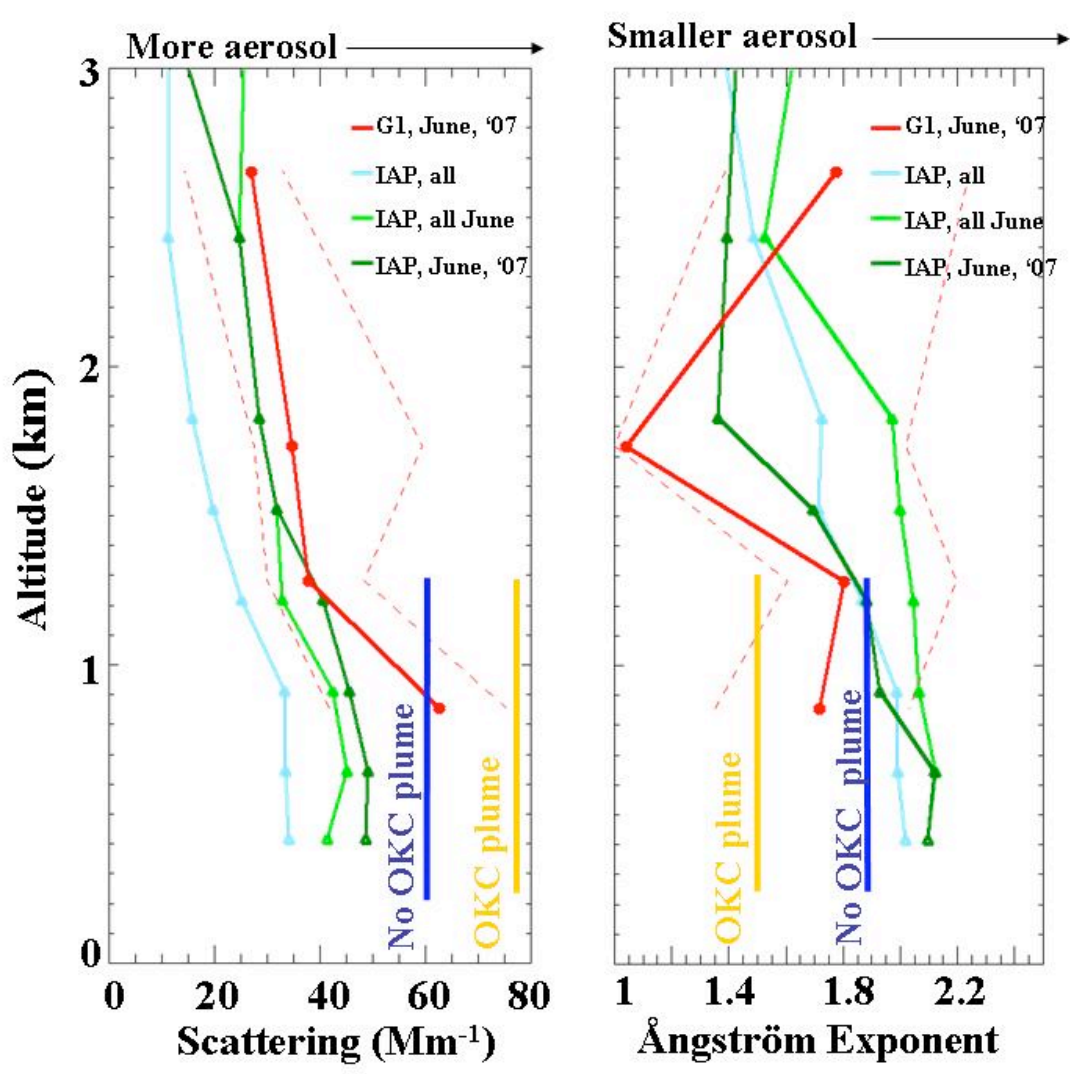

Figure 6 Instrument inter-comparison (a) PSAP (b) nephelometer

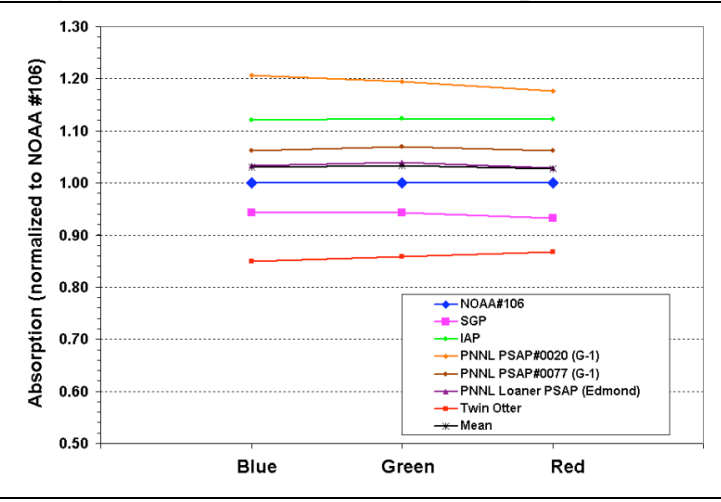

(a)

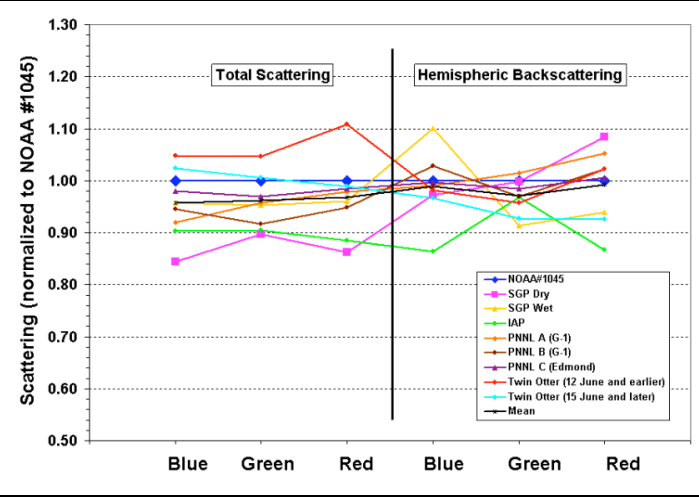

(b) 


\section{References}

Andrews, E., Lee, Y.N, Alexander, M.L., Hubbe, J.M., Ogren, J.A. “Aerosol Optical and Chemical Properties Within and Without Clouds During an Airborne Field Campaign in Central Oklahoma," American Geophysical Union, San Francisco, CA, Dec 10-14, 2007

Berg, L.K., C.M. Berkowitcz, Y.-N. Lee, X.-Y. Yu, J. Jayne, J.A. Ogren, E. Andrews, and M. L. Alexander, "Observations of aerosol chemical and optical properties during the Cumulus Humilis Aerosol Processing Study," American Meteorological Society, Phoenix, AZ, January 10-16, 2009.

Charlson, R.J., Lovelock, J.E., Andreae, M.O, Warren, S.G., "Oceanic phytoplankton, atmospheric sulfur, cloud albedo and climate," Nature, 326, 655-661, 1987

Christensson, A., J.-F. Gayet, et al "In situ observations of a reduction in effective crystal diameter in cirrus clouds near flight corridors." Geophys. Res. Lett., 27, 681-684, (2000).

Chung, S.H. and J.H. Seinfeld, "Global distribution and climate forcing of carbonaceous aerosols,” J. Geophys. Res., 107, D19, 4407, doi:10.1029/2001JD001397, 2002.

Cooke, W.F., and J.J.N. Wilson, “A global black carbon aerosol model,” J. Geophys. Res., 101 (D14), 19395-19409, 1996.

Delene D.J. and J.A. Ogren, "Variability of aerosol optical properties at four North American surface monitoring sites," J. Atmos. Sci., 59 (6): 1135-1150, 2002.

Feingold, G. and P.Y. Chuang, "Analysis of the influence of film-forming compounds on droplet growth: Implications for cloud microphysical processes and climate," J. Atmos. Sci., 59 (12), 2006-2018, 2002.

Feingold, G., and S. Kreidenweis, "Does cloud processing of aerosol enhance droplet concentrations?," J. Geophys, Res., 105 (D19), 24351-24361, 2000.

Gieray, R., P. Wieser, T. Engelhardt, E. Swietlicki, H.-C. Hansson, B. Mentes, D. Orsini, B. Martinsson, B. Svenningsson, K.J. Noone, J. Heintzenberg, "Phase partitioning of aerosol constituents in cloud based on sing-particle and bulk analysis, Atmos. Environ., 31, 2491-2502, 1997.

Hallberg, A., Ogren, J.A., Noone, K.J., Okada, K., Heingzenberg, J., and Svenningsson, I.B. "The influence of aerosol particle composition on cloud droplet formation," $J$. Atmos. Chem 19, 153-171, 1994.

Haywood, J.M., and K.P. Shine, "The effect of anthropogenic sulfate and soot aerosol on the clear sky planetary radiation budget," Geophys. Res. Lett., 22 (5), 603-606, 1995.

Heintzenberg, J., "The Po Valley Fog Experiment 1989. What have we learned, where do we go from here?" Tellus (B), 44, 443-447, 1992.

Intergovernmental Panel on Climate Change (IPCC), Climate Change 2001: The Scientific Basis, Contribution of Working Group I to the Third Assessment Report of the IPCC, Cambridge University Press, New York, 2001.

Kasper-Giebl, A., A. Koch, R. Hitzenberger and H. Puxbaum, "Scavenging efficiency of 'aerosol carbon' and sulfate in super cooled clouds at Mt. Sonnblick (3106 m a.s.1., Austria),' J. Atmos. Chem., 35, 33-46, 2000.

Kreidenweis,S.K., C. J. Walcek, G. Feingold, W. Gong, M.Z. Jacobson, C.-H. Kim, X. Liu, J.E. Penner, A. Nenes, J.H. Seinfeld "Modification of aerosol mass and size distribution due to aqueous-phase SO2 oxidation in clouds: Comparisons of several models," J. Geophys. Res., 108, (D7), 4213, doi:10.1029/2002JD002697, 2003. 
Laj, P. et al., "Behavior of $\mathrm{H} 2 \mathrm{O} 2, \mathrm{NH} 3$, and $\mathrm{BC}$ in mixed-phase clouds during CIME," Atmos. Res., 58, 315-336, 2001.

Marshall, S.F., D.S. Covert and R.J. Charlson, "Relationship between asymmetry parameter and hemispheric backscatter ratio: implications for climate forcing by aerosols," Appl. Opt., 34 (27), 6306-6311, 1995.

Noone, K. J., D. W. Johnson, et al. "A Case Study of Ship Track Formation in a Polluted Marine Boundary Layer." J. Atmos. Sci. 57(16): 2748-2764, 2000.

Noone, K.J., J.A. Ogren, A. Hallberg, H.C. Hansson, A. Wiedensohler, E. Swietlicki, “A statistical examination of the chemical differences between interstitial and scavenged aerosol," Tellus (B), 44, 581-592, 1992a

Noone, K.J., J.A. Ogren, A. Hallberg, J. Heintzenberg, J Strom, H-C Hansson, B. Svenningsson, A. Wiedensohler, S. Fuzzi, M.C. Facchini, B.G. Arends, A. Berner, "Changes in aerosol size- and phase distribution due to physical and chemical processes in fog," Tellus (B), 44, 489-504, $1992 \mathrm{~b}$.

Noone, K.J., R.J. Charlson, D.S. Covert, J.A.Ogren, J. Heintzenberg, "Cloud droplets: Solute concentration is size dependent," J.Geophys. Res., 93, D8, 9477-9482, 1988.

Noone, K.J., Hansson, H-C, Mallant, R.K.A, "Droplet sampling efficiency from crosswinds:an inlet efficiency calibration," J. Aerosol Sci., 23, 153-164, 1992c.

Ogren, J.A. and R.J. Charlson, "Elemental carbon in the atmosphere: cycle and lifetime," Tellus (B), 35, 241-254, 1983.

Ogren, J.A., J. Heintzenberg, R.J. Charlson, "In-situ sampling of clouds with a droplet to aerosol converter," Geophys. Res. Lett., 12, 121-124, 1985.

Ogren, J.A., J. Heintzenberg, A. Zuber, K.J. Noone, R.J. Charlson, "Measurements of the size-dependence of solute concentrations in cloud droplets," Tellus (B), 42, 24-31, 1989.

Ogren, J.A., E. Andrews, D.S. Covert, K.J. Noone, "Effects of cloud scavenging on single scattering albedo," Proceedings of the 14th International Conference on Clouds and Precipitation, Bologna, Italy, July, 2004.

Quinn, P. K., Bates, T.S., Clarke, A.D., Wang, W., Rood, M., Andrews, E., Allan, J., Carrico, C.M., Coffman, D., "Impact of particulate organic matter on the relative humidity dependence of light scattering: A simplified parameterization," Geophys. Res. Lett., 32, L22809, doi:101029/2005GL024322, 2005.

Rosenfeld, D., "Suppression of rain and snow by urban and industrial air pollution", Science, 287, 1793-1796, 2000.

Twohy, C. H. and B. W. Gandrud, "Electron microscope analysis of residual particles from aircraft contrails." Geophys. Res. Lett., 25(9), 1359-1362, 1998.

Wilson, J. C., and W. R. Seebaugh, "Measurement of Aerosol from Aircraft," Chapt. 30, Aerosol Measurement, 2nd Edition, Eds. P. Baron and K. Willeke, John Wiley \& Sons, 2001: 


\section{Publications}

Berg, L.K., Berkowitz, C., Ogren, J.A., Hostetler, C.A., Ferrare, R., Dubey, M., Andrews, E., Coulter, R., Hair, J., Hubbe, J., Lee, Y-N., Mazzoleni, C., Olftert, J., Springston, S., "Overview of the Cumulus Humilis Aerosol Processing Study (CHAPS)" in submitted to $B A M S$, January 2009.

\section{Presentations}

Berg,L.K., C. M. Berkowitz, J. M. Hubbe, J. Ogren, E. Andrews, and Y.-N. Lee, "Aerosol Optical Properties Observed During CHAPS," American Geophysical Union, San Francisco, CA, December15-19, 2008.

Lichtenberger, A.M., W.J. Shaw, L.K. Berg, C.M. Berkowitz, J.A. Ogren, and E. Andrews, "Digital Inversion and Initial Analysis of Nephelometer Data from the CHAPS Campaign," American Geophysical Union, San Francisco, CA, December 1519, 2008.

Ogren, J.A., E. Andrews, J. Allan, K. Bower, H. Coe, B.Corris, M. Flynn, D. Liu, W. Morgan, P. Williams, "Cloud-Processing and Aerosol Optical Properties at a Polluted Continental Site", ICCP, Cancun, Mexico, July 7-11, 2008.

Ferrare, R., M. Clayton, D. Turner, R. Newsom, C. Sivaraman, C. Hostetler, J. Hair, M. Obland, R. Rogers, A. Cook, D. Harper, W. Su, G. Schuster, L. Berg, H.Jonsson, J. Ogren, B. Andrews, "Aerosol Variability Near Clouds during CLASIC/CHAPS," ARM Science Team Meeting, Louisville, KY, March 30 to April 3, 2009.

Tomlinson, J., J. Hubbe, B. Schmid, C. Flynn, J. Ogren, E. Andrews, R. Ferrare and C. Hostetler, "The Department of Energy Airborne Facility and Programs Office Overview with an Emphasis on the G-1 Aircraft," $33^{\text {rd }}$ International Symposium on Remote Sensing of the Environment, Lago Maggiore, Italy, May 4-8, 2009.

Berg, L.K., C.M. Berkowitcz, Y.-N. Lee, X.-Y. Yu, J. Jayne, J.A. Ogren, E. Andrews, and M. L. Alexander, "Observations of aerosol chemical and optical properties during the Cumulus Humilis Aerosol Processing Study," American Meteorological Society, Phoenix, AZ, January 10-16, 2009.

Ferrare,R., M. Clayton, D. Turner, R. Newsom, C. Sivaraman, C. Hostetler, J. Hair, M. Obland, R. Rogers, A. Cook, D. Harper, W. Su, H. Jonsson, J. Ogren, E. Andrews, L. Berg, "Lidar observations of aerosols near clouds," American Meteorological Society, Phoenix, AZ, January 10-16, 2009. 